\title{
Crowdsourcing in User-Generated Content Communities: Impact of Online Networks on Perception and Intended Behaviors of Crowd Engagement
}

\author{
Ali Khalaf Mohammed Al Sukaini ${ }^{1}$, Jing Zhang ${ }^{1} \&$ Ahmed Ghanim Zghair Albazooni ${ }^{1}$ \\ ${ }^{1}$ School of Management, Huazhong University of Science and Technology, Wuhan, China \\ Correspondence: Ali Khalaf Mohammed Al Sukaini, School of Management, Huazhong University of Science and \\ Technology, Wuhan 430074, China. E-mail: Alikhalaf077@gmail.com
}

Received: March 12, 2015

Accepted: April 10, 2015

Online Published: April 20, 2015

doi:10.5430/ijba.v6n3p25

URL: http://dx.doi.org/10.5430/ijba.v6n3p25

This research is sponsored by the National Natural Science Foundation of China under Grant 71272125 and Fundamental Scientific and Research program of Chinese Central Universities under Grant 2014QN207.

\begin{abstract}
Crowd participation on online social platforms can be enhanced by crowdsourcing existence, but can also create an environment in which users are motivated by diversity of activities as sole creators and promoters of products marketing. With the fast growth of online platforms, different users have diverse viewpoints and experiences related to user-generated content (UGC) activities. Whereas previous studies on UGC have mainly hailed from company or firm perspective considering ratings, reviews, social forums, sharing videos and images, our research focuses on user-generated content as add up in crowdsourcing from users' viewpoints and experiences. In this study, variety of viewpoints of users give better understanding of users' contributions, their focus and aspirations in user-generated content.

This paper explores the extent to which users' viewpoints on using online forums from visual and non-visual content importance with mediating effects of standardization and potential of content along with moderating effects of crowdsourcing content creation and promotion legacy. We investigated the viewpoints of users on UGC media contribution as additional supplement in crowdsourcing by conducting survey of university students, one of the largest online communities in China. Findings indicate that drivers of the UGC stuff exhibit a stronger influence on crowd engagement in user-generated content networks. Concerning crowdsourcing content consistency, UGC perceptions are moderated more highly for both visual and non-visual content. This study finally crops several implications for both research and practice. Our findings contribute to a better understanding of crowdsourcing all over in user-generated content.
\end{abstract}

Keywords: crowdsourcing, digital community, User-generated content, online platforms, crowd behavioral intention

\section{Introduction}

For the intersection of content, search and social media, useful user-generated content (UGC) serves fuel to content marketing solution for firms through crowdsourcing. In order to integrate users or consumers involved in creating quality contents, firms are opening their boundaries to engage social communities - asking and answering questions and sharing content (Boudreau et al., 2011; Enkel et al., 2009). Crowdsourcing provides an opportunity to intact with intellect crowds to crowdsource content through asking online communities suggestions for products, social question $\&$ answers, contests in which users produce their own videos and share images and blog interactions (Poetz \& Schreier, 2012; Jeppesen \& Lakhani, 2010; Berthon, Pitt \& Campbell, 2008). There has been an emergence of digital consumers and users who turn creative ideas into crowdsourcing. According to Howe (2006), crowdsourcing is the contribution of different networks of people and in other way crowdsourcing is the act of taking job in a new way from crowd. Crowd can be defined as large set of anonymous individuals (Surowiecki, 2005) and wisdoms of such crowd will lead to the better solution (Robson \& Rew, 2010). Mobile based online social applications and mobile social networks (MSN's) are increasingly attracted by users for contributions (Yufeng W. \& Jianhua M, 2014). 
Various search engines and apps are the primary drivers for mobile devices use for crowdsourcing and online community participation.

The emerging superpower with huge population, China has the potential to reach impressive shares in crowdsourcing. The potential reach of crowdsourcing and the practice in China show how important it will be in future business. With inclusion of 500 million smart phones users, mobile internet in China is stimulating the citizens to turn their mobile devices for information. In main land China, $80 \%$ of internet users access Web via their smart phones and using services like instant messaging platforms such as Tencent's WeChat and payments modes (Liau, ZDNet, 2014). According to China Internet Network Information Center, the rapid growth in smartphone increased consumption of video, music and instant messaging apps over the past two years. After invention of World Wide Web in 1991, China was quick to get connected to it and to open up to the outer world through customer based technologies (Christopher R. Hughes, Gudrun Wacker, 2003). With the evolution of Internet broadly called Web 2.0, development of digital cameras, smartphones and other friendly user soft wares equipped with storage and computational resources made possible to generate innovative ideas. One of the key factors driving the Internet today is digital behavior showing an urgent need for mobile digitalization by Internet users and more than 50 percent of internet users in Mainland China are below 25 years of age. The increasing digitalization has allowed the online communities to soar in collaborative platforms that are enabling efficient collection and sharing of contributions. In global online social networks, platforms like Facebook, twitter, Wikipedia and other search engines are consumed by online communities. Chinese society runs alternatives of these sites like 'Baidu Encyclopedia', 'Qzone' the most popular social network around the world whose users are almost only Chinese, and others 'Weibo, Sina' works like Twitter, Renren and Youku. The growing demand of mobile instant messaging apps such as WeChat, Weibo, qzone and renren are indicating the rapid consumption of mobile apps for online activities. Chinese users are also much more likely to welcome interacting with products and their contents than Western consumers and $77 \%$ of Chinese web users like to note the rating of products on social media while only $15 \%$ of North Americans trust on social media for brand posts (Kate, facegroup, 2013). Mostly user-generated content is done on smartphones and other mobile devices and in Chinese society mobile technology is preferred to be in touch with others. The participatory culture through mobile devices is increasing day by day and this has changed the marketing strategies.

Users are creating easily potential contents apart from commercial routines and content is regarded as a source of information (OECD, 2007). Existing research on UGC has mainly focused on benefits of contents contribution through online review system, social blogs comments, videos sharing, peer recommendations and ratings (Cheong \& Morrison, 2008; Ertimur \& Gilly, 2012). In marketing spheres, most research has been fastened in e-commerce on word of mouth (WoM) and electronic word of mouth (eWoM) capacities (Smith et al, 2005). Recently UGC culture characterized by fascinating new media technologies has been anchored in Chinese youth and have become popular and ideas of user-generated content media is copied from world leading social media websites. The tendency of participation and aspirations to contribute in online activities is different in Chinese characteristic way from other countries (Yang et al., 2011). The importance of UGC have become clear to many business firms and marketing operators, little is known about the drivers that influence the users to participate in content production.

This study considers the important drivers that inspire users to participate in content production in Chinese society. The objective is to examine the extent and pattern of participants to contribute to UGC on Chinese digital media which is ancillary to crowdsourcing. A comprehensive conceptual framework of the relevant determinants is explored and various research hypotheses are tested. The results exhibit guidelines for researchers and marketing operates to pursue online communities for more productive UGC.

Our study thereby contributes two new perspectives to determinants of users' inclination to UGC in Chinese context: First it explores the influence of drivers on users to generate contents and media participation. Second, it explores the moderating role of language and focus material in crowdsourcing on determinants of users' tendency.

The rest of the paper is organized as follows. Section 2 provides an overview of related works on UGC as well as importance of UGC for crowdsourcing in marketing communication explaining conceptual framework and formulation of hypotheses. In section 3, we provide methodology and procedure of data collection following measures. We then describe results in section 4 and managerial implications, limitations, conclusion and proposed future work is discussed in section 5 .

\section{Related Work}

In this section we focus on reviewing previous research on exploring UGC a concept sharing similarities with crowdsourcing. Most existing research on UGC undertakes content creation under content distribution that can be considered interchangeably contribution to crowdsourcing and UGC (Kozinets et al., 2010; Afuah \& Tucci, 2012). 
Although UGC and crowdsourcing indeed share some similarities, they also significantly differ from each other. Both UGC and crowdsourcing reflect participative online activities in marketing strategies and brand related content (UGB) (Berthon et al., 2008; Engangement db, 2009; Kaplan \& Haenlein, 2010). However, the two concepts of crowdsourcing and UGC make difference in content activities depending on whether is generated voluntarily or determining specific task (Estelles \& Gonzalez, 2012; Erickson et al., 2012). External crowds among online communities produce content and diversity of views which fuel to crowdsourcing in products and services (Bingham \& Spradlin, 2012; Brabham, 2013). With greater variety in the UGC of ideas and comments, the ideas are subsidiary to crowdsourcing (Poetz \& Schreier, 2012, Smith et al., 2012).

Social media has altered the marketing communication not only in China but all over the world. Online applications have become revolutionary trend with advanced communication and media technologies (Kozinets et al., 2008). User-generated content is usually referred to user-created content or user-generated media (Kaplan \& Haenlein, 2010). According to OECD working party report (2007), user-generated content is applied to describe the various forms of media content that is online, publicly available over the internet reflecting certain amount of creative efforts.

Many studies on the effect aspect of UGC focusing on enhancement of products or services have shown co-creating activities influence on consumers (Cova, 1997). Similarly Jang et al., (2008) demonstrate the effects of co-creating activities on products and services. Co-creation by users creates value for products and imprint influence in marketing communication of a product (Schau et al., 2009). Furthermore work done by Muniz and Schau, (2007) depicts that user-generated content can create innovation in business. Another research by Shah and Tripsas (2007) reflect that products value can be established with the help of user-generated content and Fuller et al. (2007) presents that user-generated content with specific activities are the depiction of creativity to design for firms. One more research by Shah and Smith (2011), who aims to address the users as innovators having product ideas and are streaming towards their own businesses.

Looking at contributions of online communities to innovative ideas, user-generated content emerge as created goods equipped with productive ideas for firms (von Hippel et al., 2012). Most of the present research of UGC is based on the influence of user-generated content on products (Bickart \& Schindler, 2001; Chakraventy et al., 2010; von Hippel et al., 2012) and value creation of brands as innovative output (Smith, Menon \& Sivakumar, 2005; Muniz \& Schau, 2007; Cheong \& Morrison, 2008; Kozinets et al., 2010). Culture and social norms also have effect on users intended behavior to contribute in social media. The pattern and inspiration of user-generated content is different across countries.

The majority of research on UGC in one way or other addresses the importance of user ideas as contribution for user driven firms. Different from these studies, our work in Chinese context considers more on drivers that pursue users to participate including different perspectives of online platforms practice. Most importantly, we see our study as initial step in connection of crowdsourcing with user-generated content.

\subsection{Conceptual Framework and Formulation of Hypotheses}

Recently, the influence of user-generated content and intended behavior users on online platforms has attracted both media and industry (Turel \& Zhang, 2011; Kong, Kwok \& Fang, 2012). The related literature on how users are influenced by experiences and observations while engaging within the UGC websites. In this regard, it may be more appropriate to examine the crowdsourcing phenomenon by incorporating communities intended behavior of crowd engagement (Cho et al., 2010; Yang \& Lai, 2011).

User-generated content refers to social Q\&A, social blogs, discussion forums, chats apps, wikis, peer reviews, ratings, digital images, social audio and videos social networks. Further user-generated content is divided into visual and non-visual content. The visual content corresponds to images, videos, shapes, colors and objects etc. the non-visual content corresponds to the written information that is related to image but appearance of image is not there and it is only depicted in description way. Both visual and non-visual content is important to influence social network users and visual culture is more prompting adopting as social and cultural identity. We hypothesize:

H1a: UGC stuff has positive impact on contribution to visual content.

H1b: UGC stuff has positive impact on contribution to non-visual content.

\subsubsection{Mediating Effects of Drivers of UGC Effectiveness}

On social networks, users elevate new level of responsibility and interact with similar social contents (Havenstein, 2007). Social objects and prompt language is important to make users concern to adopt integration to accept volunteer contributors (Prahalad \& Ramaswamy, 2004). Chinese users depict social behavior and take effect of 
'guanxi' networking on UGC websites (Yang \& Adamic, 2011). Previous studies also report that user's behavior to engage in UGC show a higher inspiration from standardized and potential eminence of relevant contents.

\section{Standardization}

Online networks' affect leads to opinions of users for standardization of UGC. Standardization equipped with language diversity counts as social objects indicating variation and new ideas, slogans showing prompt attraction, cultural similarity interpreting trust on networks and visual appeal including design catalogue and appearance of websites.

The standardization of UGC influences users to engage in the UGC websites. If users have high inspiration of social language and tool easiness within UGC relevant to their brand related UGC (Albert et al., 2004) Therefore,

H2a. User-generated content has positive impact on standardization of UGC stuff.

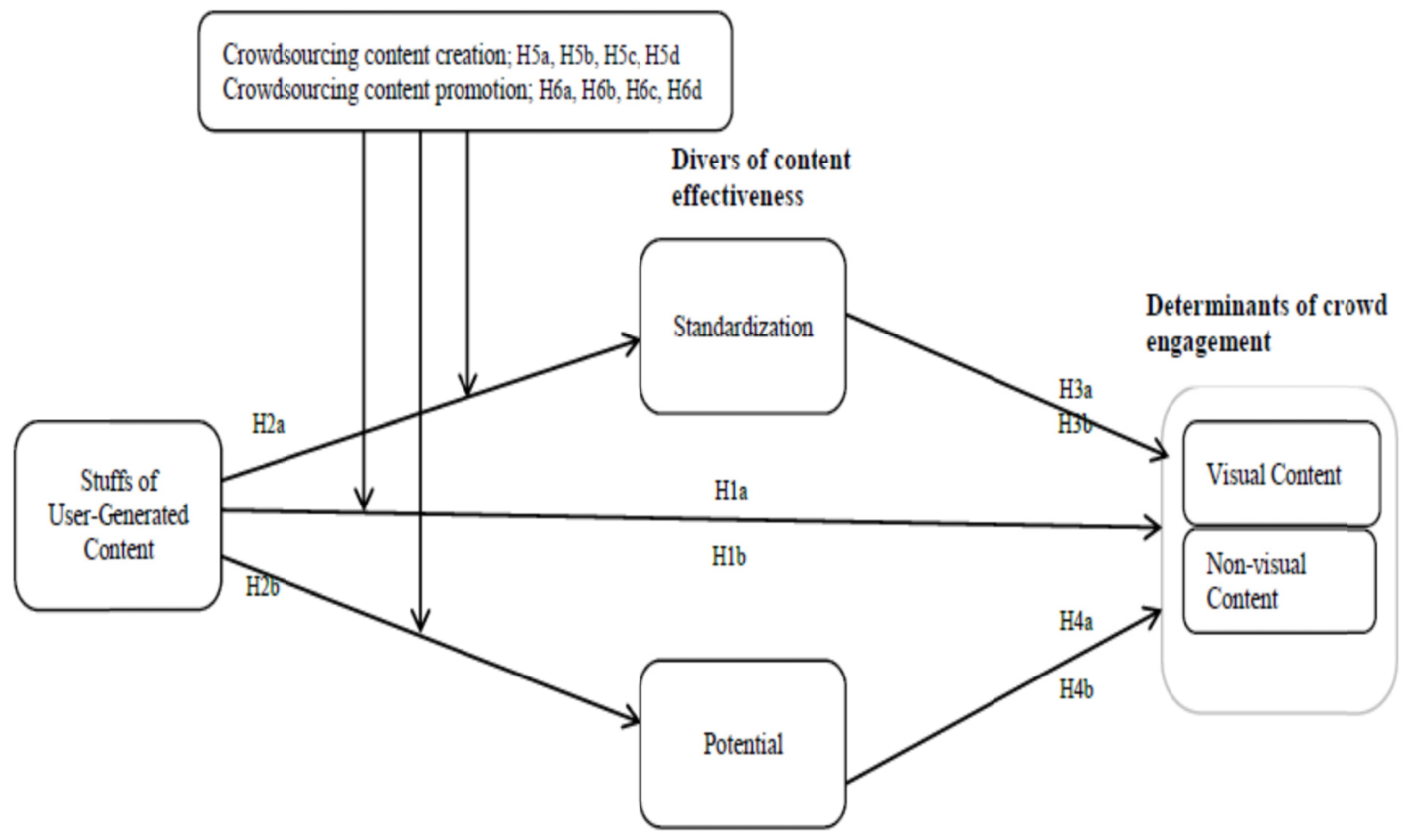

Figure 1. Research model

\section{Potential}

Potential refers to users' exploration of UGC as to make valid assertions of contents related to user experience (Luthje, 2004). The more users' engage in product related knowledge on UGC networks, the more users experience is gained (Liu et al., 2011). There 'potential' deals with network ease, easy guidance, safe, trust and better options on UGC networks for users engagement in contributions. Thus, we hypothesize:

H2b. User-generated content has positive impact on potential of UGC stuff.

UGC research shows that effective contents with appealing language and potential source has direct effect on users' engagement in contribution for UGC in both visual and non-visual content (Keller, 2007; Killian, 2008). Therefore, we formulate the following hypotheses:

H3a-b. Standardization of UGC stuff positively mediates user engagement to contribute to a) visual content b) non-visual content.

H4a-b. Potential of UGC stuff positively mediates crowd engagement to contribute to a) visual content b) non-visual content.

2.1.2 Moderating Effects - Crowdsourcing Consistency

Crowdsourcing has many areas of application but, especially it has been applied among branded products for new ideas in UGC (Leimeister et al., 2009; Poetz \& Scheier, 2012). Most studies on users' engagement through 
crowdsourcing contents have focused on text and written content ideas or solutions. Crowdsourcing content creation and content promotion is closely related to user-generated content (Liu et al., 2011).

\section{Crowdsourcing Content Creation}

Ideas presented on social media are contributions of crowd rather than formal teams (Afuah \& Tucci, 2012). Crowdsourcing is open to anyone to participate who might be having skills or context-specific determinants (Geiger et al., 2011). New ideas and innovation creation for products is applied as crowdsourcing content creation in marketing, advertising and brand building fields (Burmann, 2010; Whitla, 2009). However, we assume that crowdsourcing content creation in UGC may moderate the relationship between drivers of UGC effectiveness and determinants of crowd engagement in UGC and may have a direct impact on visual and non-visual content.

Community crowdsourcing raps in the UGC a specific crowd connected to continuously new ideas creation for products. We formulate the following hypotheses;

H5a: The effect of UGC standardization is moderated by crowdsourcing content creation. The greater the crowdsourcing content creation, the more positive the user perception of standardization in UGC.

H5b: The effect of UGC potential is moderated by crowdsourcing content creation. The greater the crowdsourcing content creation, the more positive the user perception of potential in UGC.

H5c-d: Crowdsourcing content creation moderates effect on user engagement in a) visual content b) non-visual content.

\section{Crowdsourcing Content Promotion}

Activities on UGC networks highlight the importance of collaborative efforts (Gadde et al., 2003). Crowd relies on significant mutual interest in network setting (Gadde \& Snehota, 2000) and motivation of contributors to collaborate with networks (Ritter et al., 2004). There is ongoing coordinative information of products and participatory network collaboration shadows the future significant (Poppo et al., 2007). Based on crowdsourcing promotion, we suggest the following hypotheses.

$\mathrm{H}_{6 \mathrm{a}}$ : The effect of UGC standardization is moderated by crowdsourcing content promotion. The greater the crowdsourcing content promotion, the more positive the user perception of standardization in UGC.

$\mathrm{H}_{6 \mathbf{b}}$ : The effect of UGC potential is moderated by crowdsourcing content promotion. The greater the crowdsourcing content promotion, the more positive the user perception of potential in UGC.

$\mathrm{H}_{6 \mathrm{c}-\mathrm{d}}$ : Crowdsourcing content promotion moderates effect on user engagement in a) visual content b) non-visual content.

\section{Research Methodology}

This study aims to investigate the important drivers that inspire users to contribute in user-generated content. A number of research hypotheses are proposed in the context of crowdsourcing content and UGC. A quantitative survey study was entrenched in an online questionnaire. Details about participants, data collection procedure and measures are reported in the following section.

\subsection{Participants and Data Collection Procedure}

Survey data were collected from online communities of social networks in Mainland China. The sampling population of interest consisted of users that utilize UGC networks on regular basis. University students in China participated voluntarily in the study. Participants were contacted via e-mails and link of web based online survey was distributed through e-mails to 500 students. Anther e-mail was sent as reminder after two weeks and after such efforts, a total of 205 valid responses were retrieved. The survey questionnaire was consisted of two parts, the first part was about respondents' demographic including age, gender and popular Chinese social network pattern of usage, the second part was consisted of main variables.

\subsection{Measurement}

The questions and items included in online questionnaire were set up and some adapted from prior studies and most of items were self-developed by researchers. The items and statements adapted from previous studies were modified to fit into the specification of research context. The scales of measurement for all constructs were expressed on seven point Likert scales, affixed " 1 = strongly disagree" to " 7 = strongly agree".

\section{Dependent Variables}

To measure the extent to which UGC influences users' standpoints on contribution to visual and non-visual content and effect on standardization and potential of contents worth. Three items are used to measure this construct. 
Therefore, one item was adapted from Morgan and Farsides (2009) and two items are developed by researchers with reference to content potentials on social platforms.

\section{Mediating Variables}

The drivers of effectiveness of UGC are categorized into two major dimensions, standardization and potential. These constructs are measured on seven point likert scale using three items for each dimension. Two items for standardization were self-developed and one item is adapted from Wasko and Faraj (2005). Three items for measurement of potential construct are self-developed.

\section{Moderating Variables}

Crowdsourcing content creation and promotion influence the relationship between UGC stuff and determinants of UGC crowd engagement. Additionally, crowdsourcing content creation and promotion also moderates relationship between UGC stuff and drivers of UGC effectiveness (Standardization and Potential). To measure crowdsourcing content creation, one item is adapted from Bock et al. (2008) and two items are self-developed. To measure crowdsourcing content promotion construct, three items were adapted from Wixom et al. (2005), Feller et al. (2008) and Xu et al. (2008).

\section{Control Variables}

In our analysis, we include control variables as age, gender and duration of network use. These variables are used to analyze the user effects differ with regard to these controls.

\section{Demographic analysis}

The percentage of UGC platforms as shown in figure 2, among the respondents it reflects that simultaneously $92 \%$ of users use chat networks, $80 \%$ use photos and video sharing networks, search and social Q\&A networks are used by $90 \%$ respondents and $98 \%$ use retailing networks while $85 \%$ use social blogs.

Among the respondents, $63.41 \%$ are males and $37.12 \%$ are female. Nearly half of the respondents $47.31 \%$ are aged between 18 to 22 years, $30.19 \%$ aged between 23 to 27 years and in 28 to 32 age brackets $22.92 \%$ respondents participated. In terms of education attaining, $130(64.35 \%)$ respondents are from graduate studies, $50(24.75 \%)$ are from master studies and $25(12.37 \%)$ are from PhD studies. Majority respondents, $68.31 \%$ have UGC networks experience more than 4 to 6 years. Table 1 describes the demographic profiles of the respondents.

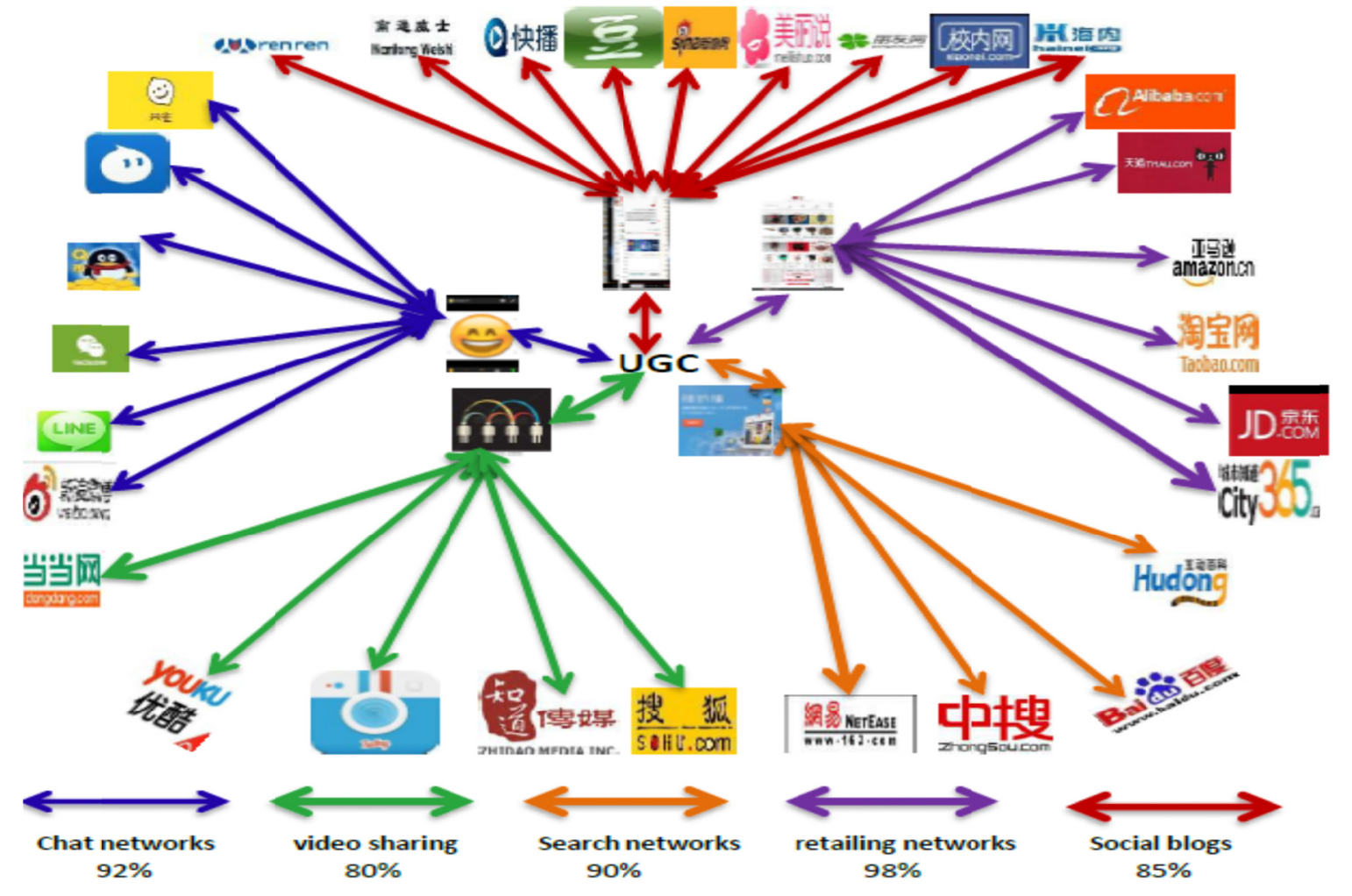

Figure 2. UGC Chinese social networks 
Table 1. Demographic profile

\begin{tabular}{|c|c|c|}
\hline Characteristics & Frequency $(N=205)$ & Percentage $(\%)$ \\
\hline \multicolumn{3}{|l|}{ Gender } \\
\hline Male & 130 & 63.41 \\
\hline Female & 75 & 37.12 \\
\hline \multicolumn{3}{|l|}{ Age } \\
\hline $18-22$ & 97 & 47.31 \\
\hline $23-27$ & 61 & 30.19 \\
\hline $28-32$ & 47 & 22.92 \\
\hline \multicolumn{3}{|l|}{ Education level } \\
\hline Under graduation & 130 & 64.35 \\
\hline Master & 50 & 24.75 \\
\hline $\mathrm{PhD}$ & 25 & 12.37 \\
\hline \multicolumn{3}{|l|}{ Experience with networks } \\
\hline $1-3$ years & 52 & 25.74 \\
\hline 4-6 years & 138 & 68.31 \\
\hline $7-9$ years & 15 & 7.42 \\
\hline
\end{tabular}

\section{Results}

To explore possible associations between constructs in the proposed model, first the measurement model is examined to evaluate reliability and validity of constructs.

Measurement model

Confirmatory factor analysis (CFA) is conducted together with the wording of the items and latent constructs to determine the reliability and validity of the model. Convergent validity of the measurement model can be assessed through composite reliability and the average variance extracted (Hair et al., 1998). While to measure a given factor, composite reliability indicates internal consistency (CR) and average variance extracted (AVE) indicates the amount of variance captured by a construct (Fornell \& Lareker, 1981). Discriminant validity indicates the extent of difference of given construct from other constructs.

Table 2. Reliability and convergent validity

\begin{tabular}{|c|c|c|c|c|c|c|}
\hline Constructs & $\begin{array}{l}\text { Cronbach's } \\
\text { alpha }\end{array}$ & CR & AVE & Items & Loading & $T$ - statistics \\
\hline \multirow[t]{3}{*}{ UGC sources } & 0.896 & .94 & .87 & $\begin{array}{l}\text { UGC sources are effective to get new ideas } \\
\text { and creativity }\end{array}$ & .92 & 23.39 \\
\hline & & & & $\begin{array}{l}\text { UGC sources are effective because of } \\
\text { cultural and language similarity }\end{array}$ & .94 & 24.97 \\
\hline & & & & $\begin{array}{l}\text { UGC sources are effective because of } \\
\text { functioning and appearance }\end{array}$ & .95 & 29.46 \\
\hline \multirow[t]{3}{*}{ Standardization } & 0.832 & .85 & .66 & $\begin{array}{l}\text { I contribute on UGC because of secure and } \\
\text { safe networks }\end{array}$ & .83 & 22.71 \\
\hline & & & & $\begin{array}{l}\text { I contribute on UGC because we have trust } \\
\text { on it }\end{array}$ & .90 & 24.09 \\
\hline & & & & $\begin{array}{l}\text { I contribute on UGC because we are } \\
\text { committed to it }\end{array}$ & .70 & 23.75 \\
\hline \multirow[t]{3}{*}{ Potential } & 0.806 & .88 & .71 & $\begin{array}{l}\text { I contribute on UGC because it is easy } \\
\text { guidance. }\end{array}$ & .84 & 14.43 \\
\hline & & & & I contribute on UGC for better options & .84 & 19.88 \\
\hline & & & & $\begin{array}{l}\text { I contribute because product promotion is } \\
\text { easy on UGC }\end{array}$ & .85 & 19.90 \\
\hline \multirow[t]{3}{*}{$\begin{array}{l}\text { Crowdsourcing } \\
\text { content creation }\end{array}$} & 0.820 & .91 & .77 & $\begin{array}{l}\text { I contribute because content creation is } \\
\text { productive }\end{array}$ & .92 & 24.19 \\
\hline & & & & $\begin{array}{l}\text { The catalogues and appearance of websites } \\
\text { peruse me to contribute for content creation }\end{array}$ & .87 & 12.66 \\
\hline & & & & $\begin{array}{l}\text { I contribute for priority promotion of } \\
\text { products }\end{array}$ & .75 & 18.29 \\
\hline \multirow[t]{3}{*}{$\begin{array}{l}\text { Crowdsourcing } \\
\text { content promotion }\end{array}$} & 0.890 & .93 & .80 & $\begin{array}{l}\text { I explore other users contents for } \\
\text { information }\end{array}$ & .91 & 22.97 \\
\hline & & & & UGC reflects expertise of other users & .90 & 12.46 \\
\hline & & & & UGC meets variety of needs & .89 & 26.73 \\
\hline
\end{tabular}


In Table 2, all measures display acceptable thresholds. Factor loading and factor reliabilities indicate satisfactory convergent validity (>.6) (Bagozzi \& Youjae, 1988) and average variance extracted also show higher value than .5 (Hair et al., 2006). The Cronbach's alpha of the construct and composite reliability both exceed the benchmark of 0.7 , confirming constructs and items reliability.

As suggested by Fornell and Larcker (1981) discriminant validity does not exceed 1 and Table 3 indicates that diagonal elements meet the criterion of discriminant validity for the constructs, establishing since all square roots of AVEs are much larger than construct correlation.

Table 3. Descriptive statistics and correlation matrix

\begin{tabular}{llllllllllll}
\hline & Mean & S.D. & 1 & 2 & 3 & 4 & 5 & 6 & 7 & 8 \\
\hline 1 & UGC sources & 4.69 & 1.51 & .94 & & & & & & & \\
2 & Standardization & 4.46 & 1.19 & $.46^{* *}$ & .77 & & & & & & \\
3 & Potential & 5.89 & 1.49 & $.36^{* *}$ & $.62^{* *}$ & $\mathbf{. 8 4}$ & & & & & \\
4 & $\begin{array}{l}\text { Crowdsourcing } \\
\text { content creation }\end{array}$ & 4.02 & 1.94 & $.20^{*}$ & $.43^{* *}$ & $.46^{* *}$ & .87 & & & & \\
5 & & & & & & & & & & \\
& $\begin{array}{l}\text { Crowdsourcing } \\
\text { content promotion }\end{array}$ & 2.60 & 1.42 & $.58^{* *}$ & $.21^{* *}$ & $.52^{* *}$ & $.44^{* *}$ &. $\mathbf{8 9}$ & & & \\
6 & & & & & & & & & & \\
7 & Age & .497 & .50 & .06 & .03 & .02 & .01 & .07 & 1 & & \\
8 & Gender & .503 & .50 & -.11 & .08 & .11 & .03 & -.00 & .13 & 1 & \\
\hline
\end{tabular}

$* *<.01$ level, $*<.05$ level

- Bold numbers on diagonal indicate the square root of average variance extracted for each construct.

The descriptive statistics for constructs with higher mean score indicate they were highly evaluated by respondents and correlations between any pair of constructs show more positive correlation.

\section{Effects of UGC stuff}

Linear regression is conducted to analyze the effects of UGC stuff on crowd in Table 4. A significant positive effect of UGC stuff on crowd contribution to visual content $(\beta=1.19, \mathrm{p}<.10)$ and to non-visual content $(\beta=.78, \mathrm{p}<.10)$ supporting $\mathrm{H} 1 \mathrm{a}$ and $\mathrm{H} 1 \mathrm{~b}$. There is significant positive effect of UGC stuff on standardization of content $(\beta=.37, \mathrm{p}$ $<.01)$ and on potential of content $(\beta=.26, \mathrm{p}<.01)$ providing support for $\mathrm{H} 2 \mathrm{a}$ and $\mathrm{H} 2 \mathrm{~b}$. Duration of networks use as control variable has not any significant impact on visual and non-visual content.

Table 4. Hypothesized main effects

\begin{tabular}{|c|c|c|c|c|c|}
\hline \multicolumn{3}{|c|}{ Hypotheses } & $\begin{array}{l}\text { Path } \\
\text { coefficient }\end{array}$ & $t$ value & $\begin{array}{l}\text { Hypothesis } \\
\text { supported }\end{array}$ \\
\hline \multicolumn{6}{|c|}{ Main Effects of online content } \\
\hline H1a & UGC stuff & Visual content & 1.19 & $14.36^{* * *}$ & Yes \\
\hline $\mathrm{H} 1 \mathrm{~b}$ & UGC stuff & Non-visual content & .78 & $13.18^{* * *}$ & Yes \\
\hline $\mathrm{R}^{2}$ & $($ Visual content $)=.25$ & $\mathrm{R}^{2}($ Non-visual content $)=.17$ & & & \\
\hline $\mathrm{H} 2 \mathrm{a}$ & UGC stuff & Standardization & .37 & $2.74^{*}$ & Yes \\
\hline $\mathrm{H} 2 \mathrm{a}$ & UGC stuff & Potential & .26 & $1.52 *$ & Yes \\
\hline Control & Duration of network use & $\begin{array}{l}\text { Visual \& non-visual } \\
\text { content }\end{array}$ & .11 & 0.96 & control \\
\hline $\mathrm{R}^{2}$ & \multicolumn{5}{|c|}{$($ Standardization $)=.43 ; \quad \mathrm{R}^{2}($ Potential $)=.22$} \\
\hline
\end{tabular}

Significant at the $1 \%$ level (one-sided test).

Significant at the $5 \%$ level (one-sided test).

Significant at the $10 \%$ level (one-sided test). 


\section{Mediating effects of drivers of UGC effectiveness}

We applied a multiple mediation model to test the mediation effects of standardization (H3a, H3b) and potential of content $(\mathrm{H} 4 \mathrm{a}, \mathrm{H} 4 \mathrm{~b})$. The model uses test of mediation to know direct effect of standardization and potential on contribution to visual and non-visual content. We found a significant positive effect of standardization $(\beta=.42$, $\mathrm{p}>.01)$ and potential $(\beta=.28, \mathrm{p}>.05)$ on contribution to visual content providing support for H3a and H4a.

Analysis regarding the second dependent variable - the willingness to share and forward the video - provides similar results. There is significant impact of standardization $(\beta=.11, \mathrm{p}<.10)$ and potential $(\beta=.25, \mathrm{p}<.10)$ on contribution of non-visual content, leading to support of $\mathrm{H} 3 \mathrm{~b}$ and $\mathrm{H} 4 \mathrm{~b}$.

\section{Moderating effects of Crowdsourcing}

\section{Crowdsourcing content creation}

To test the moderating effects, path analysis are conducted to know the effects of crowdsourcing on drivers and determinants of UGC. The results are presented in Table 5. Crowdsourcing content creation has a significantly higher effect on visual content $\left(\Delta \chi^{2}{ }_{(1)}=5.91, \mathrm{p}<.01\right)$ compare to non-visual content $\left(\Delta \chi 2_{(1)}=3.29, \mathrm{p}<.05\right)$. Crowdsourcing content creation has significant impact on potential $\left(\Delta \chi^{2}{ }_{(1)}=5.26, \mathrm{p}<.01\right)$ as compare to on standardization $\left(\Delta \chi^{2}{ }_{(1)}=3.54, \mathrm{p}<.01\right)$. Hence, we support $\mathrm{H}_{5 \mathrm{a}}, \mathrm{H}_{5 \mathrm{~b}}, \mathrm{H}_{5 \mathrm{c} \text { and }} \mathrm{H}_{5 \mathrm{~d}}$.

Table 5. Moderation effects of crowdsourcing content creation and promotion

\begin{tabular}{|c|c|c|c|c|c|}
\hline Hypothesized path & & $\beta$ high & $\beta$ low & $\Delta \chi^{2} \quad(1 d f)$ & Hypotheses \\
\hline $\begin{array}{l}\text { Crowdsourcing content creation } \\
\text { Standardization }\end{array}$ & $\longrightarrow$ & $.69^{* *}$ & $.79 * *$ & $3.54 * *$ & $\mathrm{H} 4 \mathrm{a}$ \\
\hline $\begin{array}{l}\text { Crowdsourcing content creation } \\
\text { Potential }\end{array}$ & $\rightarrow$ & $.47 * *$ & $.28 * *$ & $5.26^{* *}$ & $\mathrm{H} 4 \mathrm{~b}$ \\
\hline $\begin{array}{l}\text { Crowdsourcing content creation } \\
\text { Visual content }\end{array}$ & $\rightarrow$ & $.46^{* *}$ & $26^{* *}$ & $5.91 * *$ & $\mathrm{H} 4 \mathrm{c}$ \\
\hline $\begin{array}{l}\text { Crowdsourcing content creation } \\
\text { Non-visual content }\end{array}$ & $\rightarrow$ & $.40^{*}$ & $.36^{*}$ & $3.29 *$ & $\mathrm{H} 4 \mathrm{~d}$ \\
\hline $\begin{array}{l}\text { Crowdsourcing content promotion } \\
\text { Standardization }\end{array}$ & $\longrightarrow$ & $.26^{* *}$ & $.37 * *$ & $5.70 * *$ & $\mathrm{H} 5 \mathrm{a}$ \\
\hline $\begin{array}{l}\text { Crowdsourcing content promotion } \\
\text { Potential }\end{array}$ & $\rightarrow$ & $.32 * *$ & $.28^{* *}$ & $4.94 * *$ & $\mathrm{H} 5 \mathrm{~b}$ \\
\hline $\begin{array}{l}\text { Crowdsourcing content promotion } \\
\text { Visual content }\end{array}$ & $\rightarrow$ & $.37 * *$ & .16 & $4.55^{*}$ & $\mathrm{H} 5 \mathrm{c}$ \\
\hline $\begin{array}{l}\text { Crowdsourcing content promotion } \\
\text { Non-visual content }\end{array}$ & $\rightarrow$ & $.26^{*}$ & .05 & $5.11 *$ & $\mathrm{H} 5 \mathrm{~d}$ \\
\hline
\end{tabular}

$\beta$ represents the unstandardized path coefficient for that group.

$* \mathrm{p}<.05 ; * * \mathrm{p}<.01$

\section{Crowdsourcing content promotion}

Crowdsourcing content promotion has higher significant effect for standardization $\left(\Delta \chi^{2}{ }_{(1)}=5.70, \mathrm{p}<.01\right)$ as compare to potential $\left(\Delta \chi^{2}{ }_{(1)}=4.94, \mathrm{p}<.01\right)$. We find that crowdsourcing content promotion also has more significant impact on non-visual content $\left(\Delta \chi^{2}(1)=5.11, \mathrm{p}<.05\right)$ as to visual content $\left(\Delta \chi^{2} 2_{(1)}=4.55, \mathrm{p}<.05\right)$. On basis of this, $\mathrm{H}_{6 \mathrm{a}}, \mathrm{H}_{6 \mathrm{~b}}, \mathrm{H}_{6 \mathrm{c}}$ and $\mathrm{H}_{6 \mathrm{~d}}$ are supported.

\section{Discussion and Implications}

The current study supplies an empirical contribution through moderators of crowd engagement in user-generated content and in crowd generated content. The study outlines the evolution of perceptions of users and impact of UGC stuff empirically using perceptions of respondents from Mainland China. Additionally, the moderating effects of crowdsourcing consistency are surveyed. 
The findings of this study provide key drivers of the UGC stuff that exhibit a stronger influence on crowd engagement in user-generated content networks. However, taking a closer look, the findings show more significant impact of UGC to visual content. Concerning crowdsourcing content consistency, UGC perceptions are moderated more highly for both visual and non-visual content. The measurement model is confirmed with adequate convergent and discriminant validity and findings also indicate crowdsourcing content creation are perceived highly than crowdsourcing content promotion for standardization and potential of UGC stuff. Overall, our findings relativize crowdsourcing content in UGC stuff perceive more superiority than normal UGC appraisals.

UGC networks based on crowdsourcing initiatives provide contribution to content and pursue crowd to contribute. This study contributes to existing literature in two ways; first focusing on standardization and potential of UGC stuff investigating the perceptions of crowd to visual and non-visual content. Second, our study examines the moderating impact of crowdsourcing content creation and promotion in UGC stuff. This work is exclusive add up with crowdsourcing content in previous studies on social networks (Cheung \& Lee, 2010; Chakravarty, Lio \& Mazumdar, 2010; Cheong \& Morrison, 2008; Smith, Menon \& Sivakumar, 2005).

Our results suggest the relevance of drivers of UGC stuff effectiveness (standardization \& potential) as mediating drivers effecting on crowd intention to contribute with respect to visual and non-visual content. These findings confirm previous studies outcomes and provide support for crowd generated content for more standardization and potential contents (Cox et al, 2009; Dhar \& Chnag, 2009; Kozinets et al., 2010).

However, our research indicates that crowdsourcing content creation and promotion moderate relationship between content creation and visual, non-visual content contribution. Our moderation analysis provide support for literature on UGC stuff with crowd generated content as potential add up of this research (von Hippel et al., 2012; Berthon, Pitt \& Campbell, 2008). With addition of crowd generated content as potential and standardized contribution may influence more on perceptions of users' behavioral contribution intention rather than routine UGC stuff as indicated by past literature (Poorisat et al., 2008; Luthje, 2004).

Previous research focus on non-visual content as more contributed stuff in UGC; our findings are also aligned with previous studies (Metzger, Flanagin \& Medders, 2010) but our results shift attention from non-visual content to visual content as more effective on behavioral intention of crowd to contribute or to get inspired.

\subsection{Practical Implications}

Crowdsourcing contents are not much studied in literature and in this regard, this study is the initial step to get some insights of crowd behavior. This study is a rich contribution to emerging phenomenon of crowdsourcing for academic discussion on the one hand and on the other hand, it holds important implications for firms in brand management decisions for social media marketing, advertising and communication. It is important for crowdsourcing managers to involve crowd digital communities in creative and innovative contents to establish worth of UGC stuff. More specifically, it is important for crowdsourcing community managers in Mainland China to increase crowd participation for more innovative application as Chinese young generation access more social media sites than others. This research also provides insights for practitioners to make the designated tasks related to visual and non-visual content in crowdsourcing communities, more attractive to let the participants act in creative way.

Another important implication rests on the findings that for companies and agencies, there is need to increase online activities more versatile because of more blogging and UGC networks in similar culture and language. Standardization and potential are proven as most important drivers of UGC stuff effectiveness. Although prior studies demonstrated UGC leave positive and negative impacts of products and services (Li et al., 2006. The implication of this study is also different for companies to include more visual content and digital promotional activities on social networks. In addition, more interaction between crowdsourcing community managers and crowd will increase promotional activities of companies to integrate with creative crowd.

\subsection{Limitations and Future Research}

Our research is also subject to certain limitations and provides direction for future research. This study is conducted on possible social networks in Mainland China, and all crowdsourcing communities are not considered. In addition, Chinese social media has more of an oligopoly market than other countries, where to trace behavioral intentions of communities to contribute in crowdsourcing content is somewhat need more depth insights with cultural context in terms of variance in behavioral contribution.

Future studies should therefore explicitly manipulate all UGC networks in cultural context. It is also notable that behavioral intention literature is having gap in previous studies (Bagozzi, 2007) and cultural effects on language 
similarity content may affect the actual contribution behavior in China (Yang \& Liu, 2014). This would allow us to further investigate psychological intervention in collective cultural in contribution.

Past literature suggests that context tend users to rely on UGC (Sussan, Gould \& Weisfeld, Spolter, 2006). Hence, future research may extend further with relationship of context consideration. Moreover, experiences of crowd on different brand or service for crowdsourcing context would be interesting (Fuchs et al., 2013).

\section{Conclusion}

With the rise of crowd sourcing through social networks, communities are regarded as contributors for the success of crowdsourcing. This study has made an academic and practical contribution in this field. The current study provides a number of interesting insights into crowd engagement and moderating links between UGC and behavioral intentions of crowd for authenticity of social networks.

\section{References}

Afuah, A., \& Tucci, C. L. (2012). Crowdsourcing as a Solution to Distant Search. Academy of Management Review, 355-375. http://dx.doi.org/10.5465/amr.2010.0146

Albert, T. C., Goes, P. B., \& Gupta, A. (2004). GIST: A model for design and management of content and interactivity of customer-centric web sites. MIS Quarterly, 28(2), 161-182.

Bagozzi, R. P. (2007). The legacy of the technology acceptance model and a proposal for a paradigm shift. Journal of the Association for Information Systems, 8(4), 244-254.

Bagozzi, R. P., \& Yi, Y. (1988). On the Evaluation of Structural Equation Models. Journal of the Academy of Marketing Science, 16, Spring, 74-94. http://dx.doi.org/10.1007/BF02723327

Berthon, P., Leyland, P., \& Colin, C. (2008). When Customers Create the Ad. California Management Review, 50(4), 6-31. http://dx.doi.org/10.2307/41166454

Bickart, B., \& Robert, M. S. (2001). Internet Forums as Influential Sources of Consumer Information. Journal of Interactive Marketing, 15(3), 31-40. http://dx.doi.org/10.1002/dir.1014

Bingham, A., \& Spradlin, D. (2012). Open Innovation Marketplace: Creating Value in the Challenge Driven Enterprise. FT Press, Upper saddle River, NJ.

Bock, G., Sabherwal, R., \& Qian, Z. (2008). The effect of social context on the success of knowledge repository systems. IEEE Transactions on Engineering Management, 55(4), 536-551. http://dx.doi.org/10.1109/TEM.2008.927824

Boudreau, K., Lacatera, N., \& Lakhani, K. (2011). Incentives and problem uncertainty in innovation contests: an empirical analysis. Management Science, 57(5), 843-863. http://dx.doi.org/10.1287/mnsc. 1110.1322

Brabham, D. C. (2013). Crowdsourcing. MIT Press, Cambridge, MA.

Burmann, C. (2010). A call for 'user-generated branding'. Journal of Brand Management, 18(1), 1-4. http://dx.doi.org/10.1057/bm.2010.30

Chakravarty, A., Liu, Y., \& Mazumdar, T. (2010). The Differential Effects of Online Word-of-Mouth and Critics' Reviews on Pre-Release Movie Evaluation. Journal of Interactive Marketing, 24(3), 185-97. http://dx.doi.org/10.1016/j.intmar.2010.04.001

Cheong, H. J., \& Margaret, A. M. (2008). Consumers' Reliance on Product Information and Recommendations Found in UGC. Journal of Interactive Advertising, 8(2), 1-29. http://dx.doi.org/10.1080/15252019.2008.10722141

Cheung, C. M. K., \& Lee, M. K. O. (2010). A theoretical model of intentional social action in online social networks. Decision Support Systems, 49(1), 24-30. http://dx.doi.org/10.1016/j.dss.2009.12.006

Cho, H., Chen, M. H., \& Chung, S. (2010). Testing and integrative theoretical model of knowledge sharing behavior in the context of Wikipedia. Journal of the American Society for Information Science and Technology, 61(6), 1198-1212.

Christopher, R. H., \& Gudrun, W. (2003). China and the Internet: Politics of the Digital Leap Forward. Tailor \& Francis Group, New York. 
Cova, B. (1997). Community and Consumption: Towards a definition of the "linking value" of product or services. European Journal of Marketing, 31(3/4), 297-316. http://dx.doi.org/10.1108/03090569710162380

Cox, C., Burgess, S., Sellitto, C., \& Buultjens, J. (2009). The Role of User-Generated Content in Tourists' Travel Planning Behavior. Journal of Hospitality Marketing \& Management, 18(8), 743-64. http://dx.doi.org/10.1080/19368620903235753

Dhar, V., \& Chang, E. A. (2009). Does Chatter Matter? The Impact of User-Generated Content on Music Sales. Journal of Interactive Marketing, 23(4), 300-7. http://dx.doi.org/10.1016/j.intmar.2009.07.004

ENGAGEMENT dB. The world's most valuable brands. Who's most engaged? ENGAGEMENT dB Ranking the Top 100 Global Brands Prepared by: www.ENGAGEMENTdb.com July 2009.

Enkel, E., Gassmann, O., \& Chesbrough, H. (2009). Open R\&D and open innovation: exploring the phenomenon. R\&D Management, 39(4), 311-316. http://dx.doi.org/10.1111/j.1467-9310.2009.00570.x

Erickson, L. B., Petrick, I., \& Trauth, E. M. (2012). Hanging with the right crowd: matching crowdsourcing need to crowd characteristics. In Proceedings of the Eighteenth Americas Conference on Information Systems, August 9-12, Seattle, Washington.

Ertimur, B., \& Gilly, M. C. (2012). So Whaddya Think? Consumers Create Ads and Other Consumers Critique Them. Journal of Interactive Marketing, 26(3), 115-30. http://dx.doi.org/10.1016/j.intmar.2011.10.002

Estellés-Arolas, E., \& Gonzalez-Ladron-de-Guerva, F. (2012). Towards an integrated crowdsourcing definition. Journal of Information Science, 38(2), 189-200. http://dx.doi.org/10.1177/0165551512437638

Feller, J., Finnegan, P., Fitzgerald, B., \& Hayes, J. (2008). From Peer Production to Productization: A Study of Socially Enabled Business Exchanges in Open Source Service Networks. Information Systems Research, 19(4), 475-493. http://dx.doi.org/10.1287/isre.1080.0207

Fornell, C., \& Larcker, D. (1981). Evaluating structural equation models with unobservable variable and measurement error. Journal of Marketing Research, 18(1), 39-50. http://dx.doi.org/10.2307/3151312

Fuchs, C., Emanuela, P., Martin, S., \& Darren, W. D. (2013). All That Is Users Might Not Be Gold: How Labeling Products as User-Designed Backfires in the Context of Luxury Fashion Brands. Journal of Marketing, 1-47.

Füller, J., Marius, K. L., \& Jawecki, G. (2007). How Brands Enchant: Insights from Observing Community Driven Brand Creation. In Annual North American Conference. Association for Consumer Research, Memphis, USA.

Gadde, L. E., \& Snehota, I. (2000). Making the most of supplier relationships. Industrial Marketing Management, 29(4), 305-316. http://dx.doi.org/10.1016/S0019-8501(00)00109-7

Gadde, L. E., Huemer, L., \& Håkansson, H. (2003). Strategizing in industrial networks. Industrial Marketing Management, 32(5), 357-364. http://dx.doi.org/10.1016/S0019-8501(03)00009-9

Geiger, D., Seedorf, S., Schulze, T., Nickerson, R., \& Schader, M. (2011). Managing the crowd: Towards a taxonomy of crowdsourcing processes. Proceedings of the Seventeenth Americas Conference on Information Systems, Detroit, Michigan, August 4th-7th.

Hair, J. F., Anderson, R. E., Tatham, R. L., \& Black, W. C. (1998). Multivariate data analysis. Upper Saddle River, NJ: Prentice-Hall.

Hair, J. F., William, C. B., Babin, B. J., Anderson, R. E., \& Tatham, R. L. (2006). Multivariate Data Analysis. Upper Saddle River, NJ: Prentice Hall.

Havenstein, H. (2007). Revolt against Digg Tests User Content Model. Computerworld, 41(1).

Howe, J. (2006). The Rise of Crowdsourcing. WIRED, 14(6), 176-183.

Jang, H., Olfman, L., Ko, I., Koh, J., \& Kim, K. (2008). The influence of online brand community characteristics on community commitment and brand loyalty. International Journal of Electronic Commerce, 12(3), 57-80. http://dx.doi.org/10.2753/JEC1086-4415120304

Jeppesen, L. B., \& Lakhani, K. (2010). Marginality and problem-solving effectiveness in broadcast search. Organization Science, 21(5), 1016-1033. http://dx.doi.org/10.1287/orsc.1090.0491

Kaplan, A, M., \& Haenlein, M. (2010). Users of the world, unite! The challenges and opportunities of Social Media. Business Horizons, 53, 59-68. http://dx.doi.org/10.1016/j.bushor.2009.09.003 
Kate, D. (2013). Take Advantage of Crowdsourcing in China. Retrieved September 25, 2014, from http://www.facegroup.com/blog/take-advantage-of-crowdsourcing-in-china.html

Keller, Ed. (2007). Unleashing the Power of Word of Mouth: Creating Brand Advocacy to Drive Growth. Journal of Advertising Research, 47(4), 448-52. http://dx.doi.org/10.2501/S0021849907070468

Killian, V. Idea Storm Fortnightly Recap 9-19-08; Retrieved September 30, 2008, from http://direct2dell.com/one2one/archive/2008/09/19/ideastorm-fortnightly-recap-9-19-08.aspx

Kong, J. S. L., Kwok, R. C. W., \& Fang, Y. (2012). The effects of peer intrinsic and extrinsic motivation on MMOG game-based collaborative learning. Information \& Management, 49, 1-9. http://dx.doi.org/10.1016/j.im.2011.10.004

Kozinets, R. V., Hemetsberger, A., \& Schau, H. J. (2008). The Wisdom of Consumer Crowds: Collective Innovation in the Age of Networked Marketing. Journal of Macro marketing, 28(4), 339-54. http://dx.doi.org/10.1177/0276146708325382

Kozinets, R. V., Valck, K. de, Wojnicki, A. C., \& Wilner, S. J. S. (2010). Networked Narratives: Understanding Word-of-Mouth Marketing in Online Communities. Journal of Marketing, 74, 71-89. http://dx.doi.org/10.1509/jmkg.74.2.71

Leimeister, J. M., Hubert, M., Bretschneider, U., \& Krcmar, H. (2009). Leveraging crowdsourcing: Activation-supporting components for IT-based ideas competition. Journal of Management Information Systems, 26(1), 197-224. http://dx.doi.org/10.2753/MIS0742-1222260108

Li, D., Browne, G. J., \& Wetherbe, J. C. (2006). Why do Internet users stick with a specific web site? A relationship perspective. International Journal of Electronic Commerce, 10(4), 105-141. http://dx.doi.org/10.2753/JEC1086-4415100404

Liau, Yun, Q. (2012, July 31). Baidu, Sina enter mobile partnership. Retrieved August 25 ${ }^{\text {th }}$, 2014, from http://www.zdnet.com/article/baidu-sina-enter-mobile-partnership/

Liu, Q. B., Karahanna, E., \& Watson, R. T. (2011). Unveiling user-generated content: Designing websites to best present customer reviews. Business Horizons, 54(3), 231-240. http://dx.doi.org/10.1016/j.bushor.2011.01.004

Luthje, C. (2004). Characteristics of Innovating Users in a Consumer Goods Field: An Empirical Study of Sport-Related Product Consumers. Technovation, 24(9), 683-95. http://dx.doi.org/10.1016/S0166-4972(02)00150-5

Metzger, M. J., Flanagin, A. J., \& Medders, R. B. (2010). Social and Heuristic Approaches to Credibility Evaluation Online. Journal of Communication, 60(3), 413-39. http://dx.doi.org/10.1111/j.1460-2466.2010.01488.x

Morgan, J., \& Farsides, T. (2009). Measuring Meaning in Life. Journal of Happiness Studies, 10, 197-214. http://dx.doi.org/10.1007/s10902-007-9075-0

Muñiz, Jr., A. M., \& Schau, H. J. (2007). Vigilante Marketing and Consumer-Created Communications. Journal of Advertising, 36(3), 187-202.

OECD. (2007). Working Party on the Information Economy. OECD. (2007). Participative web and user-created content: Web 2.0, wikis, and social networking. Paris: Organisation for Economic Co-operation and Development.

Poetz, M. K., \& Schreier, M. (2012). The value of crowdsourcing: can users really compete with professionals in generating new product ideas? Journal of Product Innovation Management, 29(2), 245-256. http://dx.doi.org/10.1111/j.1540-5885.2011.00893.x

Poorisat, T., Detenber, B. H., Viswanthan, V., \& Nofrina, H. (2008). Perceptions of Credibility: A Comparison of User-Generated and Expert-Generated Websites. International Communication Association (ICA) Annual Conference. Chicago, IL: International Communication Association (ICA).

Poppo, L., Zhou, K. Z., \& Rhu, S. (2007). Alternative origins to interorganizational trust: An Interdependence perspective on the shadow of the past and the shadow of the future. SSRN Electronic Journal. http://dx.doi.org/10.2139/ssrn.975472

Prahalad, C., \& Ramaswamy, V. (2004). The future of competition: co-creating unique value with customers. Boston MA: Havard Business School Press, p.256. 
Ritter, T., Wilkinson, I. F., \& Johnston, W. J. (2004). Managing in complex business networks. Industrial Marketing Management, 33(3), 175-183. http://dx.doi.org/10.1016/j.indmarman.2003.10.016

Robert, V. K. (2008). Technology/Ideology: How Ideological Fields Influence Consumers' Technology Narratives. Journal of Consumer Research. http://dx.doi.org/10.1086/523289

Robson, N., \& Rew, D. (2010). Collective wisdom and decision making in surgical Oncology. European Journal of Surgical Oncology, 36(3), 230-236. http://dx.doi.org/10.1016/j.ejso.2010.01.002

Schau, H. J., Albert, M. M., \& Arnould, E. J. (2009). How Brand Community Practices Create Value. Journal of Marketing, 73(5), 30-51. http://dx.doi.org/10.1509/jmkg.73.5.30

Shah, S., \& Tripsas, M. (2007). The accidental entrepreneur: The emergent \& collective process of user entrepreneurship. Strategic Entrepreneurship Journal, (1), 123-140.

Shah, S. K., Smith, S. W., \& Reedy, E. J. (2011). Who are user entrepreneurs? Findings on innovation, founder characteristics \& firm characteristics. Kauffman Foundation Report. Kansas City, MO: Kauffman Foundation.

Smith, A. N., Eileen, F., \& Chen, Y. J. (2012). How Does Brand-Related User-Generated Content Differ across Youtube, Facebook, and Twitter?. Journal of Interactive Marketing, 26(2), 102-13. http://dx.doi.org/10.1016/j.intmar.2012.01.002

Smith, D., Menon, S., \& Sivakumar, K. (2005). Online Peer and Editorial Recommendations, Trust, and Choice in Virtual Markets. Journal of Interactive Marketing, 19(3), 15-37. http://dx.doi.org/10.1002/dir.20041

Surowiecki, J. (2005). The Wisdom of Crowds. Anchor Books.

Sussan, F., Gould, S., \& Weisfeld-Spolter, S. (2006). Location, Location, Location: The Relative Roles of Virtual Location, Online Word -of-Mouth. (eWom) and Advertising in the New-Product Adoption Process. Advances in Consumer Research, 33, 649-50.

Turel, O., \& Zhang, Y. (2011). Should I e-collaborate with this group? A multilevel model of usage intentions. Information \& Management, 48, 62-68. http://dx.doi.org/10.1016/j.im.2010.12.004

von Hippel, Eric, A., Füller, J., \& Schroll, R. (2012). User Generated Brands and their Contribution to the Diffusion of User Innovations (October 7, 2012). MIT Sloan Research Paper No. 4877-11. http://dx.doi.org/10.2139/ssrn.1756941

Wang, Y. F., \& Ma, J. H. (2014). Mobile Social Networking and Computing: A Multidisciplinary Integrative Perspective. CRC Press, Tailor \& Francis, New York.

Wasko, M. M., \& Faraj, S. (2005). Why should I share? Examining social capital and knowledge contribution in electronic networks of practice. MIS Quarterly, 29(1), 35-57.

Whitla, P. (2009). Crowdsourcing and its application in marketing activities. Management, 5(1), 15-28.

Wixom, B. H., \& Todd, P. A. (2005). A theoretical integration of user satisfaction and technology acceptance. Information Systems Research, 16(1), 85-102. http://dx.doi.org/10.1287/isre.1050.0042

Xu, D. J., Liao, S. S., \& Li, Q. (2008). Combining empirical experimentation and modeling techniques: A design research approach for personalized mobile advertising applications. Decision Support Systems, 44, 710-724. http://dx.doi.org/10.1016/j.dss.2007.10.002

Yang, H. L., \& Lai, C. Y. (2011). Understanding knowledge sharing behaviour in Wikipedia. Behaviour \& Information Technology, 30(1), 131-142. http://dx.doi.org/10.1080/0144929X.2010.516019

Yang, J., Ackerman, M. S., \& Adamic, L. A. (2011). Virtual gifts and guanxi: supporting social exchange in a Chinese online community. Proceeding of the ACM conference on Computer supported cooperative work, Hangzhou, China, pp. 45-54.

Yang, Q., \& Liu, Y. (2014). What's on the other side of the great firewall? Chinese Web users' motivations for bypassing the Internet censorship. Computers in Human Behavior, 37, 249-257. http://dx.doi.org/10.1016/j.chb.2014.04.054 